\title{
CASE REPORT Management of Intracranial Pressure Control in Reciprocal Grade 3 Astrocytoma Patients in Dr. Moewardi General Hospital Surakarta
}

\author{
Eko Setijanto ${ }^{*}$, Teddy Wijaya ${ }^{*} \bowtie$
}

Article Info :

Submitted :

27-08-2021

Accepted :

17-10-2021

Published :

30-10-2021

https://dx.doi.org/10.20

$\underline{\text { 961/soja.v1i2.49731 }}$

Authors' affiliations:

*Department of

Anesthesiology and

Intensive Therapy,

Medical Faculty, Universitas Sebelas

Maret, Surakarta, Indonesia

${ }^{\boxplus}$ Correspondence: teddywijaya33@yahoo. com

\begin{abstract}
Surgery in patients with astrocytoma is performed based on the size of the tumor in the brain and the functional status of the patients. Management of patients with intracranial hypertension can be guided by monitoring intracranial pressure (ICP) perioperatively. A variety of ventricular, intraparenchymal, and subdural equipment can be installed by neurosurgeons to provide ICP measurements.

We reported a 50-year-old female patient, with a complaint of having a speech disorder since four years ago. Preoperative physical examination showed GCS E4V5M6, patient's body mass index was $29.29 \mathrm{~kg} / \mathrm{m}^{2}$ (obese). Patient's physical status was assessed with ASA 3. There was no significant abnormality in laboratory examination. MRI Brain contrast examination showed solid cystic lesion in supratentorial left temporal lobe with size $2.3 \times 3.5 \times 4.7 \mathrm{~cm}$ accompanied by broad perifocal edema in the left frontal, temporal and parietal lobe. The chest X-ray showed cardiomegaly and pneumonia. Electrocardiography showed normal sinus rhythm.

Craniotomy in patients with astrocytoma is performed based on the size of the tumor in the brain and the functional status of the patient. Preoperative evaluation for patients undergoing craniotomy should be carried out to determine the presence or absence of intracranial hypertension. In principle, postoperative management in the ICU is to control the respiratory system, optimize the cardiovascular system, and prevent possible complications. Management of intracranial pressure control in reciprocal grade 3 astrocytoma patient should be paid attention to various things and consider the condition of the patients. Preoperative preparations, as well as perioperative and postoperative monitoring, should be carefully observed to prevent complications that will adversely affect patients.
\end{abstract}

Keywords: intracranial pressure control; reciprocal astrocytoma; anesthesia

Copyright @ 2021 Authors. This is an open access article distributed under the terms of the Creative Commons Attribution- 4.0 International License (http:// https://creativecommons.org/licenses/by/4.0/) 


\section{INTRODUCTION}

Intracranial mass may be congenital, neoplastic (benign or malignant), infectious (abscesses or cysts), or vascular (hematoma or arteriovenous malformations). ${ }^{1}$ Craniotomy is commonly performed for brain neoplasms. Primary tumors usually arise from glial cells (astrocytoma, oligodendroglioma, or glioblastoma), ependymal cells (ependymoma), or supporting tissues (meningioma, schwannoma, or choroid papilloma). Childhood tumors include medulloblastoma, neuroblastoma, and astrocytoma. $^{1,2}$

Surgery in patients with astrocytoma is performed based on the size of the tumor in the brain and the functional status of the patients. ${ }^{3}$ Patients with tumors located in vital centers with hemiparesis, dysphasia/aphasia, elderly patients are not an indication for surgery. ${ }^{4}$

The role of surgery is to decompress the tumor mass and take the tissue for histopathological examination, so that adjuvants treatment can be planned and estimate the prognosis. ${ }^{4}$
Management of patients with intracranial hypertension can be guided by monitoring intracranial pressure (ICP) perioperatively. ${ }^{4}$ A variety of ventricular, intraparenchymal, and subdural equipment can be installed by neurosurgeons to provide ICP measurements. ${ }^{4,5}$

\section{CASE ILLUSTRATION}

History Taking

A 50-year-old female patient, with a complaint of having a speech disorder four years ago. Patients have a hard time saying a sentence. The patient also complains of blurred vision in the left eye.

Patients have a history of tumor excision craniotomy in August 2018 (GA-ET). The patient has a history of surgery on the head 1 year ago at Dr. Moewardi Surakarta General Hospital. Patients have no history of hypertension and diabetes mellitus. History of asthma, tightness, allergies, were also undeniable.

\section{Physical Examination}

From the physical examination, it was found GCS E4V5M6, patient's body mass index was $29.29 \mathrm{~kg} / \mathrm{m}^{2}$ (obese), other vital signs were within normal limits. There was no abnormality found in full-body 
examination. Patient physical status assessed with ASA 3.

\section{Supporting Examination}

Blood gas analysis showed an increase of $\mathrm{pH}(7,508), \mathrm{BE}(7.2), \mathrm{PO} 2$ (131.4), $\mathrm{HCO}_{3}(30.4)$, total $\mathrm{CO} 2$ (31.6), and arterial lactate (2.2). Preoperative laboratory examination (7/8/2019) showed only a slight increase of leukocyte count (11.8), while other values within normal limits. Postoperative laboratory examination (8/8/2019) showed increase of hematocrit (46\%) and increase of leukocyte count (17.5).

The results of MRI Brain contrast examination showed solid cystic supratentorial lobe temporalis sinistra lesion with size $2.3 \times 3.5 \times 4.7 \mathrm{~cm}$ accompanied by broad perifocal edema in the frontotemporoparietalis sinistra lobe that urges the left lateral ventricle as well as getting feeding artery from the left MCA M3 which is a picture of grade III astrocytoma, in addition found herniation of subfalcine 0.4 $\mathrm{cm}$ to right, as well as ventriculomegaly lateralis dextra, ventricles sinistra cornu posterior and ventricles 3 (Figure 1). The result of chest X-ray after surgery (20/8/2019) in bed showed cardiomegaly and pneumonia (Figure 2). The electrocardiography of patient showed normal sinus rhythm, 82 bpm, normoaxis (Figure 3). 


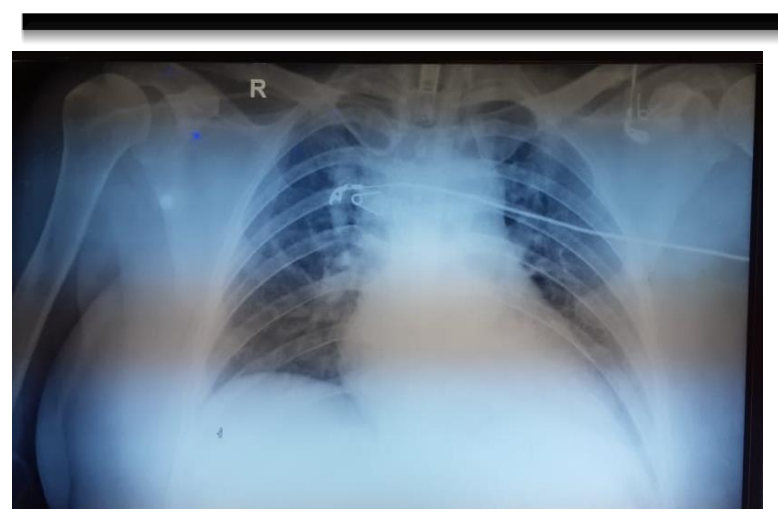

Figure 2 Chest X-ray in bed of patient.

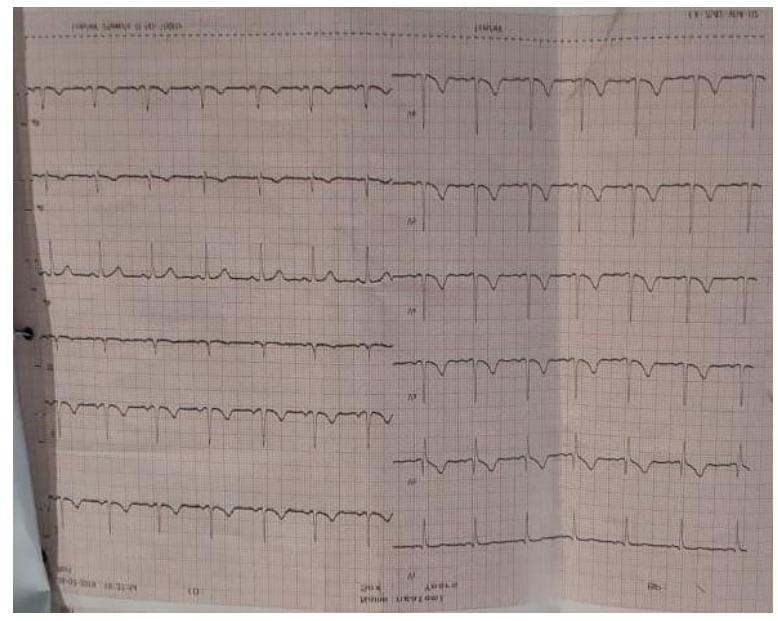

Figure 3 Electrocardiography of patient.

\section{Anesthesia Management}

The patient attached intravenousline no. $18 \mathrm{G}$ with ringer lactate infuse. In the operating room patient was mounted with ECG monitor, pulse oximetry and sphygmomanometer. Vital sign recorded: BP: 120/70 mmHg; HR: 80 x/min, RR 12 $\mathrm{x} / \mathrm{min}$, temperature $36.3^{\circ} \mathrm{C}, \mathrm{SaO}_{2}: 98 \%$ with normal.

Anesthesia begins at 7:30 a.m. with general anesthesia (invasive GA-ET) using fentanyl $200 \mathrm{mcg}$ iv, thiopental 450 $\mathrm{mg}$ iv, rocuronium $50 \mathrm{mg}$ and lidocaine $80 \mathrm{mg}$. Endotracheal tube used size 7.0, $19 \mathrm{~cm}$. The operation lasts approximately 3 hours 50 minutes until 11.20, bleeding $\pm 200 \mathrm{cc}$, urine production $\pm 900 \mathrm{cc}$, fluid balance +540 (IWL $47 \mathrm{cc} / \mathrm{h} \sim 180 \mathrm{cc}$ (3 hours 50 minutes)). Durante surgery, hemodynamic blood pressure systole 110$130 \mathrm{mmHg}$ and diastole $70-90 \mathrm{mmHg}$, pulse $70-80 \mathrm{x} / \mathrm{min}$, saturation $99-100 \%$. The patient obtains crystalloid fluid support and blood transfusion with the following details:

$\begin{array}{ll}\text { PRC 1 1 220 } & : 220 \mathrm{cc} \\ \text { Crystalloid } & \frac{: 1600 \mathrm{cc} \pm}{1820 \mathrm{cc}}\end{array}$

After the operation is complete, the patient then treated to the ICU.

\section{Postoperative Management}

In ICU, patient was positioned head up $30^{\circ}$ and administered with Paracetamol 1 gram/8 hours, tranexamic acid $150 \mathrm{mg} / 8$ hours, ranitidine $50 \mathrm{mg} / 12$ hours. Patient was also administered with ampicillin sulbactam 1,5 gram/8 hours, Mannitol 100 cc/8 hours, Phenytoin 100 mg/8 hours and Dexamethasone $5 \mathrm{mg} / 8$ hours. Patient also mounted with ventilator. 
Once stable the patient is transferred to the HCU.

\section{DISCUSSION}

\section{Preoperative Assessment}

Craniotomy in patients with astrocytoma is performed based on the size of the tumor in the brain and the functional status of the patients. ${ }^{3}$ The role of surgery is: (i) decompress the tumor mass, (ii) take tissue for histopathological examination, so that adjuvant treatment can be planned and estimate the prognosis. ${ }^{4}$

Preoperative evaluation for patients undergoing craniotomy should strive to determine the presence or absence of intracranial hypertension. ${ }^{6}$ Computed tomography (CT) and magnetic resonance imaging (MRI) scan should be reviewed for evidence of brain edema, midline shift larger than $0.5 \mathrm{~cm}$, or ventricular displacement or compression. From the MRI brain with contrast obtained solid cystic lesions supratentorial lobe temporalis sinistra size $2.3 \times 3.5 \times 4.7 \mathrm{~cm}$ accompanied by a broad perifocal edema in the left frontal, temporal, and parietal lobe that urges the left lateral ventricle as well as obtain feeding artery from the left MCA M3 which is a picture of grade III astrocytoma.
Laboratory evaluation should rule out the presence of corticosteroid-induced hyperglycemia, electrolyte disorders due to diuretics, or abnormal secretions of antidiuretic hormones. ${ }^{6}$ In laboratory tests (August 8, 2019), hemoglobin 15.1, hematocrit 46, erythrocytes 4.91 million, leukocytes 17.5, coagulation function (August 7, 2019) were normal, and electrolytes were within normal limits.

In these patients, it was found that the patient came in a compos mentis condition. On physical examination, blood pressure was obtained 140/100 mmHg, pulse $174 x / \mathrm{min}$, and RR 16x/min.

To keep the patient's condition stable, the patient is given a crystalloid infusion for fluid needs and attached a urinary catheter to assess fluid adequacy.

\section{Anesthesia Management}

In this case, a craniotomy of tumor excision is performed using general anesthesia (invasive GA-ET) using fentanyl $200 \mathrm{mcg}$ iv, thiopental $450 \mathrm{mg}$ iv, rocuronium $50 \mathrm{mg}$ and lidocaine 80 mg. Endotracheal tube used size 7.0, 19 $\mathrm{cm}$.

Hemodynamic monitoring is carried out through ECG monitors, pulse oximetry, blood pressure and pulse. 
Durante surgery, hemodynamic blood pressure systole 110-130 $\mathrm{mmHg}$ and diastole 70-90 $\mathrm{mmHg}$, pulse 70-80 x/min, saturation $99-100 \%$. The patient obtained crystalloid fluid support and blood transfusion with a total of $1820 \mathrm{cc}$.

In addition to standard monitoring, direct monitoring of intraarterial pressure and bladder catheterization are used for most patients undergoing craniotomy. ${ }^{6}$ Rapid changes in blood pressure during anesthesia procedures, positioning, and surgical manipulation are best managed with guidance from continuous invasive pressure monitoring. ${ }^{7,8}$

\section{Postoperative Management}

The patient is treated in the ICU for good monitoring of possible complications, progression of the disease and treatment before anesthesia. In principle, postoperative management in the ICU is to master the respiratory system, optimize the cardiovascular system, and prevent possible complications. $^{4}$ In this case, postoperatively, the patient was treated in the ICU in a fully conscious condition, spontaneous breath was strong but hemodynamic was still unstable.
A 50-year-old female patient with grade 3 recidivist astrocytoma ASA III pro surgery craniotomy excision tumor on August 8, 2019 with general anesthesia technique (GA-ET invasive). The operation ran for 3 hours and 50 minutes. During stable hemodynamic surgery. Postoperatively the patient was treated in the ICU for 2 days. During treatment in the ICU, the patient's hemodynamics are stable, so on the second day of postoperative weaning ventilator was performed, the patient moved to HCU.

\section{REFERENCE}

1. Louis DN, Perry A, Wesseling P, et al. The 2021 WHO Classification of Tumors of the Central Nervous System: a summary. Neuro Oncol. 2021;23(8):1231-1251.

doi:10.1093/neuonc/noab106

2. Lapointe S, Perry A, Butowski NA. Primary brain tumours in adults. Lancet (London, England). 2018;392(10145):432-446.

doi:10.1016/S0140-

$6736(18) 30990-5$

3. Lamsal R, Rath GP. Pediatric neuroanesthesia. Curr Opin Anaesthesiol. Published online 
2018.doi:10.1097/ACO.000000000 0000630

4. Kurihara M, Nishimura S. Estimation of the head elevation angle that causes clinically important venous air embolism in a semi-sitting position for neurosurgery: a retrospective observational study. Fukushima $J$ Med Sci. 2020;66(2):67-72. doi:10.5387/fms.2019-33

5. Kaplan K, Kaya Y, Kuncan M, Ertunç HM. Brain tumor classification using modified local binary patterns (LBP) feature extraction methods. Med Hypotheses. $\quad 2020 ; 139: 109696$. doi:10.1016/j.mehy.2020.109696

6. Hirtz A, Rech F, Dubois-PotSchneider $\mathrm{H}$, Dumond $\mathrm{H}$. Astrocytoma: A HormoneSensitive Tumor? Int J Mol Sci. 2020;21(23).

doi:10.3390/ijms21239114

7. Hasselblatt M, Jaber M, Reuss D, et al. Diffuse astrocytoma, IDHwildtype: A dissolving diagnosis. $J$ Neuropathol Exp Neurol. 2018;77(6):422-425. doi:10.1093/jnen/nly012
8. Gropper MA. Miller's Anesthesia. (Gropper MA, ed.). Elsevier; 2020. doi:https://doi.org/10.1016/j.bja.20 20.06.035 